\title{
A Comprehensive Understanding of Choroidal Metastasis from Lung Cancer
}

\author{
Zihan Qu* \\ Jiewei Liu* \\ Lingling Zhu \\ Qinghua Zhou \\ Lung Cancer Center, West China \\ Hospital of Sichuan University, Chengdu, \\ 61004I, Sichuan, People's Republic of \\ China \\ *These authors contributed equally to \\ this work
}

\begin{abstract}
The incidence of lung cancer with intraocular metastasis is low, of which choroidal metastasis is the most painful metastatic lesion. The clinical symptoms resulting from choroidal metastasis from lung cancer easily detected although they are rarely identified prior to the diagnosis of the primary malignancy. The quality of life of patients is inevitably impaired. Some lung cancer patients complain of ocular symptoms as the first manifestation of lung cancer. Early diagnosis and treatment can significantly overcome or delay the visual impairment and improve prognosis. The main therapeutic modalities include systemic and local treatments, while observation is also a treatment option. Currently, the feasibility and effectiveness of various treatment options are controversial worldwide. Herein, we summarize the underlying mechanisms, epidemiology, clinical features, auxiliary examinations, diagnosis, and recent treatment options for intraocular metastases.
\end{abstract}

Keywords: intraocular tumor, cancer therapeutics, systemic therapy, local therapy

\section{Introduction}

The incidence of intraocular metastases is about $8 \%-10 \%$. ${ }^{1}$ Approximately $88 \%$ of eye metastases occur in the choroid, ${ }^{2}$ with the majority originating from breast cancer $(47 \%)$ and lung cancer $(21 \%))^{2,3}$

The clinical symptoms of lung cancer with choroid metastases (CM) are apparent, and approximately $35 \%$ of ocular metastases are detected prior to diagnosis of lung cancer. ${ }^{2}$ Timely diagnosis and interventions for such patients are extremely important because of the poor prognosis.

Ocular radiotherapy is considered a standard treatment option for intraocular metastatic tumors. Subsequently, other local or systemic treatments have gradually emerged in the setting of well-established cancer therapeutics, while various treatment modalities and sophisticated combination approaches remain controversial.

\section{Epidemiology}

Metastases are the most common ocular malignancies, with the uvea being the site most often affected. Approximately, $88 \%$ of metastases occur in the posterior uvea, namely the choroid, followed by the iris $(9 \%)$, and the ciliary body $(2 \%){ }^{2}$ The distribution of posterior pole involvement of the eyeball equator is roughly temporal $(35 \%)$, upper $(22 \%)$, lower $(17 \%)$, nasal $(14 \%)$, and the macular $(12 \%){ }^{2}$ However, Freedman and Folk reported that the probability of macular area involvement was as high as $40.3 \%,{ }^{4}$ which may explain the obvious symptoms that motivate patients to attend hospital earlier.

\author{
Correspondence: Qinghua Zhou \\ 61004 \\ Tel + I-57I5238I38 \\ Email prof_qh_zhou@I26.com
}


The prevalence of symptomatic CM is less than $3 \%,{ }^{4}$ however, patients with malignancies exhibit prolonged survival time thanks to the improvement of antitumor agent and the emergence of advanced diagnostic examinations, which have allowed $\mathrm{CM}$ to be detected more frequently. Conversely, the eye is not a routine site for screening metastatic neoplasms, and the part involving metastasis does not involve the visual functional area; thus, many asymptomatic intraocular metastases may have not been diagnosed.

The most frequent pathological types of $\mathrm{CM}$ deriving from lung cancer are, in order, adenocarcinoma, small cell carcinoma, squamous cell carcinoma, large cell carcinoma, and carcinoid tumor. ${ }^{5}$ Notably, although approximately $89 \%$ of carcinoid tumors occur in the gastrointestinal tract, $10 \%$ have been reported to occur in the lung, Harbour et al determined that lung carcinoid tumors are more easily prone to $\mathrm{CM}$ than those originating from the gastrointestinal tract, with the latter more inclined to orbital metastases. ${ }^{6}$

\section{Metastatic Mechanism of Choroidal Metastases}

Why do tumor cells most often metastasize to the choroid rather than to other parts of the eye?

First, the eye is an organ with the most abundant blood perfusion in the body, and in accordance with the theory "seed and soil" proposed by Paget, ${ }^{7}$ colonization of metastases mainly depends on a suitable microenvironment and ample blood perfusion. ${ }^{8}$ Moreover, Duke-Elder and Perkins ${ }^{9}$ first demonstrated that the choroid is supplied by the short posterior ciliary artery, which has multiple branches and a rich terminal vascularization allowing more tumor emboli to reach the posterior uvea. To some extent, this explains why the choroid is more often affected than the ciliary body and sclera. ${ }^{2}$ In addition, choroidal capillary endothelial cells are loosely attached and rich in fenestrations, which is conducive to the aggregation, adhesion, and implantation of tumor cells. ${ }^{10}$ Furthermore, Stephens and Shields considered the left eye to be more likely to be affected, ${ }^{11}$ because the left internal carotid artery and ophthalmic artery are distributed at right angles. This specific anatomical structure slows the blood flow allowing the tumor thrombi to assemble. However, other studies have not recognized a similar tendency. ${ }^{4,12,13}$

\section{Clinical Characteristics}

$\mathrm{CM}$ is more common in middle-aged men in lung cancer patients with left eye involvement. ${ }^{5,14,15}$ Compared with breast cancer $(4 \%-7 \%)$, intraocular metastases of lung cancer $(25 \%-35 \%)$ are more often detected before the primary lesion. ${ }^{2,4}$ Furthermore, lung cancer is more inclined to CM (choroid: orbit, ratio: $5.7: 1) .{ }^{4}$

The median interval for lung cancer metastasis is shorter than that of breast cancer ( 276 vs. 1266 days, $\mathrm{P}<0.0001$ ), which may be related to pathological type, degree of differentiation, and aggressiveness of the primary tumor (such as lung adenocarcinoma, small cell lung cancer). ${ }^{16}$

In a retrospective study of 194 cases, CM from lung cancer were mostly unilateral (82\%) and unifocal (77\%). ${ }^{17}$ Instead, bilateral eyeball involvement has been described in a relatively larger proportion of breast cancer patients (breast cancer $68 \%$ vs. lung cancer $18 \%)^{2}$ and approximately one-third of patients present multifocal lesions. ${ }^{18}$ Meanwhile, CM originating from lung cancer is smaller in volume than that originating from breast cancer. ${ }^{4}$

The choroid is the sixth organ in order of frequency to be involved in distant metastasis of lung cancer. Approximately $70 \%-86 \%$ of patients with intraocular metastases present other sites of metastases, simultaneously. ${ }^{2,5}$ An average of three distant organs may be involved, and most commonly these sites are metastases to the bone $(59.1 \%)$, lymph nodes $(50 \%)$, liver $(40.9 \%)$, brain $(31.8 \%)$, lung $(27.3 \%)$, and adrenal glands (22.7\%), respectively. ${ }^{5}$ Only $33 \%$ of patients do not present metastases to other organs. ${ }^{19}$

Notably, CM from lung cancer has a tendency of synchronous brain metastasis with a rate of approximately $22 \%-32.5 \%,{ }^{20,21}$ compared to up to $50 \%$ in breast cancer. ${ }^{12}$ Moreover, lung cancer patients are more likely to develop $\mathrm{CM}$ in combination with one or more organ metastases. For breast cancer, combined lung and brain metastases are higher risk factors for $\mathrm{CM}$, and its incidence may increase from $5 \%$ to $11 \% .^{22,23}$ In breast cancer, most $\mathrm{CM}$ are generally asymptomatic. ${ }^{22}$ Conversely, the clinical manifestations of $\mathrm{CM}$ in lung cancer are significant. Approximately $34 \%-44 \%$ of patients tend to present ocular symptoms as an original complaint of lung cancer. $^{2,17}$

\section{Clinical Presentations and Ocular Findings}

Clinical symptoms vary greatly depending on the location of the lesion or the degree of invasion. Clinical manifestations include successively blurred vision, vision loss, flashing, floaters, metamorphopsia, and diplopia, and less 
frequently pain, red eyes, or glaucoma, among which metamorphopsia and vision loss are the most prominent. $^{24}$ Eyeball pain is always more frequent in $\mathrm{CM}$ from lung cancer than from primary uveal malignancy. ${ }^{25}$ Interestingly, compared to the less than $5 \%$ of patients with $\mathrm{CM}$ from breast cancer, about $12 \%$ of patients with metastases from lung cancer experience pain. $^{17,18}$

CM derived from lung neoplasm generally presents the following characteristics in ocular findings: uni- or multifocal mass located in the macula region or posterior to the equator, flattened or slightly elevated, and less commonly having a "mushroom-like" shape when the tumor invades Bruch's membrane. The appearance of the CM can appear as white, brown, gray, and orange in color, but the most common CM are yellow and white. ${ }^{26}$ Metastases may also have a mottled appearance on optical coherence tomography (OCT). ${ }^{27,28}$ Approximately $28 \%-73 \%$ of lesions are combined with subretinal effusion (located between the outer segment of retinal photoreceptor cells and the retinal pigment epithelium), ${ }^{26}$ which can be confined or distributed around the lesion. Furthermore, the presence of a shallow amount of subretinal fluid, which is confined to around the tumor is also a characteristic of metastases. ${ }^{29}$ Retinal detachment can also be observed in some patients with advanced tumors. ${ }^{24}$ When the optic papilla is affected, manifestations such as papilledema may be observed. ${ }^{1}$

\section{Auxiliary Examinations and Characteristic Performances}

It is challenging and limited to obtain pathological diagnosis of both lung cancer and CM. The diagnostic approach for CM can be summarized as follows: (1) lung cancer and CM by surgery or biopsy exhibit the same pathological type in both lesions, which is the gold standard; (2) primary lung malignancy is confirmed by surgery, biopsy or cytology, and fundus examination and/or imaging examination present the characteristic features of $\mathrm{CM}$; (3) chest imaging examination shows the characteristic features of lung cancer, confirmed by eyeball surgery, or anterior chamber biopsy or immunohistochemistry; (4) chest and eye imaging examinations or fundus examination shows characteristic manifestations of malignancy; and (5) exclusion of other primary cancers and primary tumors in the eye. The latter two can only be speculated to be a clinical diagnosis without pathological evidence, thus may not be adequate for anti-cancer therapy. In clinical practice, CM from lung cancer can generally be diagnosed with a combination of clinical symptoms and imaging findings. To differentiate from uveal melanoma as the most common malignant tumor and CM, slit lamp microscopy, B-mode ultrasound, fundus fluorescein angiography (FFA), optical coherence tomography (OCT) and orbit magnetic resonance imaging (MRI) auxiliary tests would be routinely performed. ${ }^{5,23,30}$ For example, the ultrasonography features of CM are flat or slightly elevated, with the medium to high homogeneity reflectivity that is higher than that of most uveal melanomas. MRI appears isointense on T1WI and hypointense on T2WI, unlike uveal melanoma exhibits high signal intensity on T1WI. ${ }^{31}$ Intraocular biopsy or fine needle anterior chamber puncture or vitrectomy biopsy is most indicated in cases where there is clinical suspicion of uveal metastasis, but a detailed systematic examination has been performed and there is still no evidence of primary malignancy Table 1 summarizes the differences between CM and melanoma on auxiliary examinations.

\section{Management Options}

Due to the advanced disease, the treatment of $\mathrm{CM}$ is usually palliative. The treatment options should be based on various factors, such as the physical condition of the patient, the location and number of primary tumors, the presence or absence of distant metastases, and the location and number of intraocular metastases. Approximately twothirds of lung cancer patients with CM may benefit from treatments; thus, early diagnosis and interventions are encouraged. $^{32}$

Therapy is roughly divided into: systemic therapies, systemic therapy combined with local therapy (for instance ocular radiotherapy and intravitreal bevacizumab), and local treatment alone. For patients with no obvious clinical symptoms, small-sized lesions, no invasion of the visual function area, or low-grade malignant tumor type (for example carcinoid tumors), close observation, and follow-up are also treatment options.

Figure 1 Summarizes the workup and treatment algorithms applied in cases of $\mathrm{CM}$ that precede the detection of primary neoplasm.

\section{Systemic Therapies}

Systemic therapy is fundamentally based on the context that CM metastasis from primary malignant lesions represents systemic disease. The strategies involve mostly 
Table I Differences Between Choroidal Metastasis and Melanoma on Auxiliary Examinations

\begin{tabular}{|c|c|c|}
\hline $\begin{array}{l}\text { Examinations/Types } \\
\text { of Ocular Tumors }\end{array}$ & Choroidal Metastasis & Choroidal Melanoma \\
\hline $\begin{array}{l}\text { B-mode } \\
\text { Ultrasonography }\end{array}$ & $\begin{array}{l}\text { Medium-high heterogenous echo mass }{ }^{96} \text { no choroidal } \\
\text { depression }^{\#,} \text { and echo attenuation; }{ }^{97} \\
\text { A flat and wide mass; height-to-base ratio (HBR):0.18; }{ }^{98} \\
\text { Widespread retinal detachment, subretinal effusion. }\end{array}$ & $\begin{array}{l}\text { Low-to-medium homogeneity echo; } \\
\text { echo attenuation and choroid 'dig hollow' } \\
\text { phenomenon }{ }^{\text {\#.97 }} \\
\text { A dome shaped or 'mushroom' configuration; * } \\
\text { Choroidal depression; }{ }^{97} \\
\text { The dense echoes suggest subretinal or suprachoroidal } \\
\text { hemorrhage;' } \\
\text { height-to-base ratio (HBR):0.6; } \\
\text { Spontaneous vascular pulsations suggest retinal or } \\
\text { choroidal hemorrhage; }{ }^{99} \text { subretinal effusion. }\end{array}$ \\
\hline $\begin{array}{l}\text { Funds Fluorescein } \\
\text { Angiography (FFA)** }\end{array}$ & $\begin{array}{l}\text { Hypofluorescence in the arterial phase; } \\
\text { Dilated retinal capillaries at the margin of the } \\
\text { arteriovenous stage, needle-like or mottled } \\
\text { hyperfluorescent leakage at the edge of the lesion from } \\
\text { early to late angiography, with visible tumor blood vessels; } \\
\text { In the venous phase, diffuse fluorescence with } \\
\text { hyperfluorescent halo or arc on the periphery. }{ }^{97} \\
\text { Lesions may show multifocal strong fluorescence changes. }\end{array}$ & $\begin{array}{l}\text { Blocked fluorescence, local hypofluorescence in the } \\
\text { arterial phase; fluorescent spots gradually increase in the } \\
\text { arteriovenous phase, and form mottled, fixed } \\
\text { fluorescence with hypofluorescent areas. } \\
\text { Tortuous, spiral tumor blood vessels and retinal blood } \\
\text { vessels sometimes are visible; Simultaneous visualization } \\
\text { of the double-circulation phenomenon, showing diffuse } \\
\text { fluorescence in the venous phase. }\end{array}$ \\
\hline $\begin{array}{l}\text { Indocyanine Green } \\
\text { Angiography (ICGA) }\end{array}$ & $\begin{array}{l}\text { On the uniform fluorescent pigment background, } \\
\text { hypofluorescent performance in the arteriovenous phase. }\end{array}$ & $\begin{array}{l}\text { No fluorescence, or few fluorescence signals in the } \\
\text { arterial phase, weak fluorescence in the venous phase, or } \\
\text { spot-like fluorescence or fusion fluorescence; } \\
\text { Large blood vessels are visible, and advanced tumors } \\
\text { present fluorescent leakage, some reveal empty } \\
\text { phenomenon or three ring image in the venous phase. }{ }^{101}\end{array}$ \\
\hline $\begin{array}{l}\text { Optical Coherence } \\
\text { Tomography (OCT) }\end{array}$ & $\begin{array}{l}\text { Uneven or wavy lesion; } \\
67 \%-95 \% \text { combined with secondary changes in the retinal } \\
\text { pigment epithelium (RPE) (such as: fine granular and } \\
\text { clumped high reflection signals in the RPE or atrophy of } \\
\text { the retinal photoreceptor cell layer, decreased acoustic } \\
\text { reflectance within the tumor, and choroidal capillaries } \\
\text { depression, }{ }^{\text {a, } 103} \text { retinal detachment, subretinal effusion }{ }^{b} \text {, } \\
\text { etc.) }\end{array}$ & $\begin{array}{l}\text { The surface is relatively smooth; } \\
\text { The retinal pigment epithelium-choroidal capillary layer } \\
\text { light band is highly raised on which multiple lumps of high } \\
\text { reflection signals can be seen }{ }^{* * *} ; \text {; }^{104} \\
\text { The elevated light band is not uniform, with dense spot- } \\
\text { like high-reflection signals, cyst-like changes can be seen in } \\
\text { the retinal nerve epithelial layer where varying degrees of } \\
\text { detachment of retinal nerve epithelial layer can be seen } \\
\text { around the tumor; } \\
\text { Subretinal effusion. }\end{array}$ \\
\hline $\begin{array}{l}\text { OCT angiography } \\
\text { (OCTA) }\end{array}$ & A lack of blood flow signal. ${ }^{106}$ & A dense and uniform blood flow signal. ${ }^{106}$ \\
\hline $\begin{array}{l}\text { Magnetic resonance } \\
\text { imaging }(\mathrm{MRI})^{\mathrm{c} /} \\
\text { Computed tomography } \\
\text { (CT) }\end{array}$ & $\begin{array}{l}\text { MRI: a well-defined choroidal mass appearing iso-intense } \\
\text { on TIWI and hypointense on } \mathrm{T}^{\mathrm{WI}}{ }^{107} \\
\mathrm{CT} \text { : focal thickening of the posterior eye segment, well- } \\
\text { demarcated, uniform high density }{ }^{97} \text { and is rarely applied. }\end{array}$ & $\begin{array}{l}\text { MRI: high intensity on TIWI and low intensity on T2WI. } \\
\text { CT: a hemispherical or spherical lesion, clear boundary, } \\
\text { uniform density, significantly homogeneous enhancement; } \\
\text { Necrosis may occur in larger tumors, showing heterogeneous } \\
\text { enhancement (no characteristic performance); } \\
\text { Shadows of iso-density within the eye and the outer wall of the } \\
\text { eyeball to the orbit for those with extra-ocular spread. }{ }^{108}\end{array}$ \\
\hline $\begin{array}{l}\text { Plasma } \\
\text { Carcinoembryonic } \\
\text { antigen (CEA) }\end{array}$ & Highly elevated CEA levels. ${ }^{109}$ & Lightly elevated CEA levels less than $10 \mathrm{ng} / \mathrm{mL} .^{1}{ }^{110}$ \\
\hline
\end{tabular}

(Continued) 
Table I (Continued).

\begin{tabular}{|c|c|c|}
\hline $\begin{array}{l}\text { Examinations/Types } \\
\text { of Ocular Tumors }\end{array}$ & Choroidal Metastasis & Choroidal Melanoma \\
\hline $\begin{array}{l}\text { Fine Needle Aspiration } \\
\text { Biopsy (FNAB) }\end{array}$ & $\begin{array}{l}\text { Abundant vacuolated cytoplasm and eccentrically located } \\
\text { nuclei with prominent nucleoli, loosely large epithelioid } \\
\text { cells; } \\
\text { IHC: positive for cytokeratin (AEI/AE3) and mucicarmine; } \\
\text { CK7 or CK20 staining help to localize a primary lesion in } \\
\text { upper or lower gastrointestinal tumors; } \\
\text { Estrogen, progesterone receptors may support primary } \\
\text { breast tumor; } \\
\text { TTF-I is a useful stain in support of a lung primary } \\
\text { tumor. }{ }^{\prime \prime \prime} \\
\text { FISH or gene testing: detection of EGFR, ALK, ROS or } \\
\text { Her-2, ER, PR. }\end{array}$ & $\begin{array}{l}\text { A relatively bland cellular appearance; } \\
\text { Cytoplasmic melanin; } \\
\text { Mixed cell type, spindle B cell }{ }^{112} \text { and epithelioid cells; } \\
\text { IHC: positive for S I00, HMB- } 45 \text {, and MART-I. }{ }^{\prime \prime \prime} \\
\text { FISH or Gene testing: loss of one chromosome } 3 \\
\text { (monosomy 3), chromosome } 8 \mathrm{q} \text { gain, chromosome IP } \\
\text { loss, chromosome } 6 \text { rearrangements. }\end{array}$ \\
\hline
\end{tabular}

Notes: ${ }^{\#}$ Because the tumor cells are rich in pigments, the absorption of sound energy is reduced. The acoustic interface of the base cannot be reflected to the transducer to be received, resulting in a lack of echoes in the base of the choroidal tumor. Therefore, a depression appears under the strong echo of the retina and choroid. ${ }^{\prime \prime}$ Due to the dilated and dense blood sinuses in the anterior part of the tumor, which gradually becomes smaller and sparse backwards, the echogenicity on the sonogram shows that the anterior edge of the tumor is dense and with a strong echo, and the intensity of the backward echoes gradually decreases, forming an echoless zone near the eyeball wall. *The larger the apical and basal dimensions, the greater the likelihood that the lesion is neoplastic. **For uveal melanoma, FFA can show the double circulation of the tumor and retinal capillary dilation, which is irreplaceable by ICGA. ${ }^{13}$ Chinese researchers believe that needle-like hyperfluorescent leakage is a characteristic feature of CM in FFA, which can be distinguished from choroidal melanoma. ${ }^{1 / 4} * * *$ This high reflex point is the tumor cells or macrophages rich in lipofuscin and melanin particles after the tumor interacts with the retina, so it may be a specific OCT manifestation of choroidal malignant tumors. ${ }^{\mathrm{a} O n l y} \mathrm{CM}$ can reveal the partial shape of small and medium vessels, and the other tumors cannot show the choroidal vascular signal. ${ }^{\mathrm{b}}$ The amount of subretinal fluid is very shallow and is adjacent to the tumor, which is another typical sign of metastatic choroidal disease. 'MRI is needed to exclude concomitant brain metastases.

Abbreviations: CEA, carcinoembryonic antigen; FFA, fundus fluorescein angiography; FNAB, fine needle aspiration biopsy; HBR, height to base ratio; IGGA, indocyanine green angiography; IHC, immunohistochemistry; OCT, optical coherence tomography; OCTA, OCT angiography; PRE, pigment epithelium.

systemic chemotherapy or tyrosine kinase inhibitors (TKIs) with or without anti-angiogenetic therapy. ${ }^{24,33-37}$

\section{Systemic Chemotherapy}

Systemic chemotherapy is necessary for patients with malignant lung carcinoma and various metastases including CM, especially for those without a drug-sensitive gene mutation and thus lose the opportunity for targeted therapies. Multifocal lesions and/or lesions near the optic disc that are not suitable for ocular radiotherapy are recommended for systemic chemotherapy. For lesions located in the anterior part of the choroid which is at greater risk of radiotherapy-related ocular complications (such as cataract), systemic chemotherapy is also recommended. The treatment strategies of chemotherapy for patients with advanced lung carcinoma should follow the guidelines of the National Comprehensive Cancer Network (NCCN), or the European Society for Medical Oncology (ESMO).

A retrospective study revealed that chemotherapy is equivalent to ocular radiotherapy in terms of reducing tumor volume, absorbing subretinal fluid, and improving vision. ${ }^{38}$ The cohort analysis conducted by Hussain et al showed that compared with patients who did not receive chemotherapy, chemotherapy significantly affected the survival rate of patients with choroidal cancer $(\mathrm{HR}=$ 0.377 , 95\% CI 0.292-0.486, $\mathrm{p}<0.001) .{ }^{39}$ Moreover, an Asian retrospective study of 12 patients with CM reported that $66.7 \%$ of patients achieved CM regression when treated with chemotherapy alone. ${ }^{24}$ Further, studies have reported that the combination of chemotherapy with intravenous bevacizumab may also be effective in cases of intraocular metastases. ${ }^{29,34,36,40,41}$

Chemotherapy should be administered early, because for elderly patients, in poor physical condition (EGOC PS $>2$ ), receiving second-line treatment or additional treatments, it is not recommended. Regular follow-up and monitoring should be conducted during treatment. If ocular symptoms deteriorate during chemotherapy, local treatments such as external beam radiation therapy (EBRT) should be carried out immediately. ${ }^{2,42}$ If systemic treatment alone can effectively control $\mathrm{CM}$ as the oligometastatic disease, local treatment might be delivered sequentially after systemic therapy to enhance efficacy. $^{43,44}$

\section{Targeted Therapy}

In lung cancer, the emergence TKIs agents targeting TKdriven oncogenic genes, such as erlotinib, gefitinib, and 


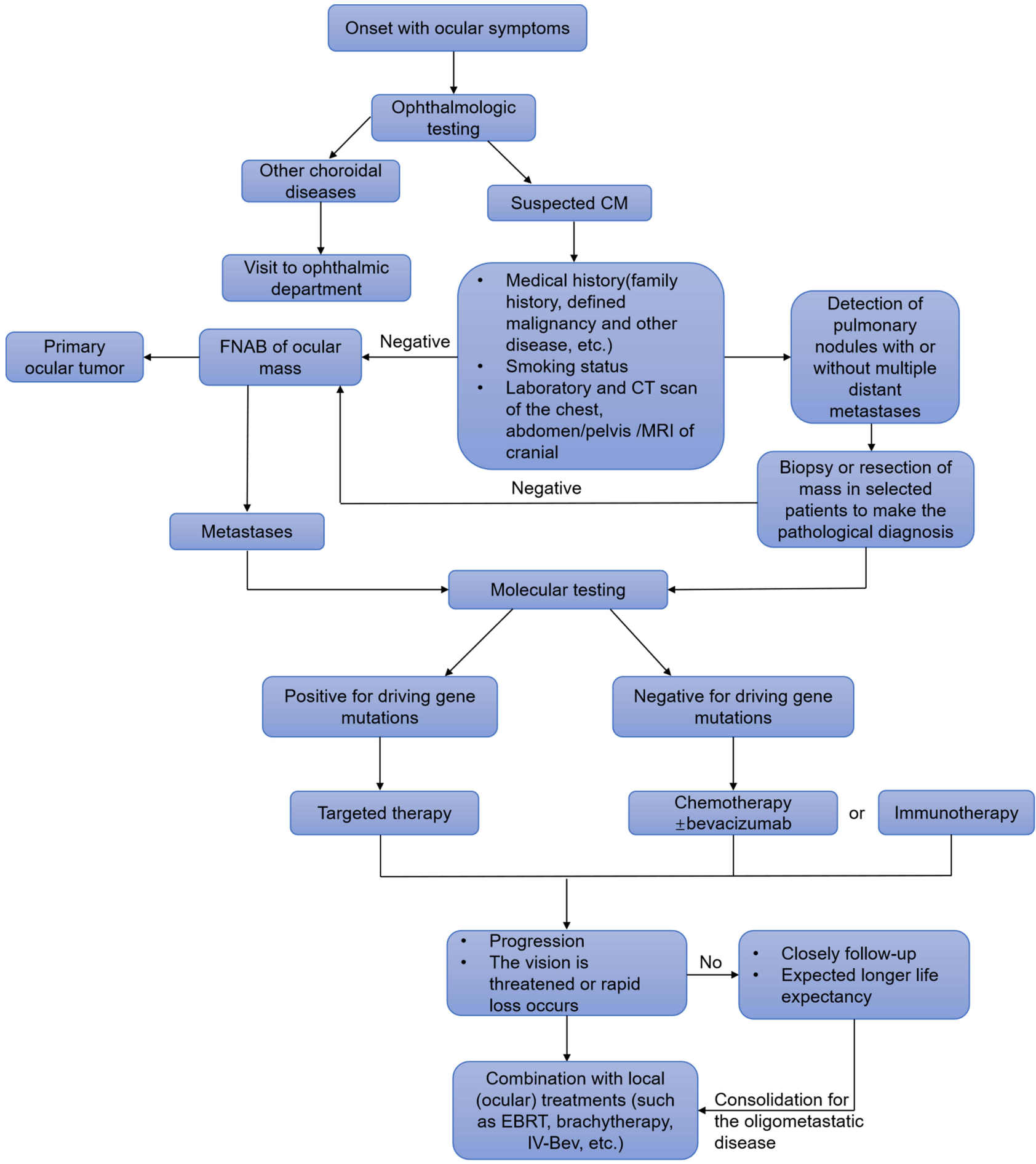

Figure I Diagnostic and treatment algorithm for CM.

Abbreviations: FNAB, fine needle aspiration biopsy; EBRT, external beam radiation therapy; IV-Bev, intravitreal Bevacizumab; CM, choroidal metastases.

crizotinib, has greatly improved patients' progression-free survival (PFS) and overall survival (OS) with milder adverse events, compared with chemotherapy. Therefore, TKI treatment is preferred for patients with CM carrying sensitive gene mutations, especially for those with an unfavorable physical condition or present contraindications or unwillingness for local treatments. The efficacy of TKI agents is equivalent to radiation, and the onset of action is shorter. ${ }^{37}$ There have also been reports of successful regression of $\mathrm{CM}$ and improvement of symptoms 
as a result of TKI combined with anti-angiogenic therapy, such as intravitreal bevacizumab. ${ }^{45,46}$ The explanation may be that EGFR and VEGF share a downstream signaling pathway, and when the activity of VEGF is downregulated by EGFR inhibitors, deactivation of VEGF simultaneously inhibits the autocrine signal of EGFR. ${ }^{47,48}$

Although there have been several reports indicating that targeted agents alone could effectively control ocular and primary lesions, ${ }^{32,49-51}$ there are still a lack of clinical trials and evidence of reporting bias, that call for further investigations and clinical practice. In addition, caution should be taken when differentiating patients receiving crizotinib complaining of ocular symptoms due to drugassociated adverse events from atypical ocular symptoms of patients with $\mathrm{CM}^{52}$

\section{Local Therapy}

Local therapies are aimed at relieving eye symptoms, maintain visual acuity, and to avoid or reduce the possibility of eyeball enucleation. When CM becomes resistant to systemic treatment, threatens vision or ocular symptoms worsen rapidly, palliative local treatments should be considered. $^{25}$ With rigorous follow-up, the patient's vision and tumor response should be monitored before deciding to start local treatments. ${ }^{30}$

\section{Local Radiotherapy}

Conventionally, radiotherapy has been considered the cornerstone for ocular malignancies. In terms of CM lesions, optional treatment strategies include external beam radiation therapy, brachytherapy, gamma knife radiosurgery $(\mathrm{GKR})$, and proton beam therapy (PBT). Each has its strengths and most suitable indications, which will be illustrated in detail below.

\section{External Beam Radiation Therapy}

External beam radiation therapy (EBRT) is applicable primarily to bilateral, multifocal tumors, accompanied by subretinal fluid or invasion of a functional region resulting in severe vision loss. ${ }^{14,34}$ The main radiation modes include the unilateral posterior globe, bilateral posterior globes, entire globe, or whole-brain plus posterior globes. ${ }^{53}$ Treatment outcome has a relatively long onset time, the average is about 6.5 months, ${ }^{14}$ and the treatment response gradually appears with the process of treatment time. Rudoler et al found that a good prognosis was associated with age younger than 55 years old, tumor diameter less than $15 \mathrm{~mm}$, and vision not less than 20/60 before treatment. ${ }^{54}$

Contralateral eyeball involvement may occur in some patients with unilateral CM patients. Rosset et al reported that initial bilateral eye irradiation may prevent new metastatic foci from developing in the contralateral eye. ${ }^{55}$ A retrospective analysis conducted by Wiegel et al revealed that unilateral irradiation is sufficient to control metastases and prevent new metastases of the contralateral eye. A careful analysis found that when a unilateral field with non-sparing of the contralateral choroid was employed, $50 \%-70 \%$ of the prescribed dose was received by the posterior contralateral choroid. ${ }^{56}$

There is a dose-effect relationship when the prescribed dose is over $35.5 \mathrm{~Gy}$, but if the dose is more than $35 \mathrm{~Gy}-$ $40 \mathrm{~Gy}$, the occurrence of radiotherapy-related side effects also increases correspondingly. ${ }^{55,56}$ A retrospective study of 483 patients demonstrated that the incidence of radiation-related side effects was about $12 \%$, and included cataract, radiation retinopathy, exposure keratopathy, optic neuropathy, neovascularization of the iris, and narrow-angle glaucoma. The incidence is susceptible to increased intraocular pressure (IOP), biopsy, and ethnic differences. $^{53}$ For patients with identifiable risk factors such as diabetes, hypertension, and older age, the sensitivity of the retina will increase even at lower doses. ${ }^{53}$ Furthermore, as lens-sparing posterior ocular irradiation is generally given, radiation cataractogenesis is not a doselimiting toxicity of ocular radiotherapy regardless of survival length. ${ }^{30}$ Side effects mostly appear 6-21 months after radiotherapy, which is longer than the median OS (5.2 months) of patients with CM, making this population more suitable for early ocular radiotherapy. ${ }^{11,14}$ When the median follow-up time is within 1 year, long-term complications are rarely observed. ${ }^{14}$ Therefore, ocular complications are more likely to develop in patients with a longer life expectancy.

\section{Brachytherapy}

In brachytherapy, known as plaque radiotherapy, radiation can be directly targeted to the tissue, with indications of small-to-medium-sized solitary lesions located in the anterior uvea and distant from the macula or optic papilla. ${ }^{34,57}$ Brachytherapy could also be used as a second-line alternative for failure of systemic treatment or progression after EBRT. $^{25}$ In addition, compared to which delivers a uniform dose to the entire eyeball, the characteristic of brachytherapy is that it allows emitting heterogeneous 
doses to the lesion. ${ }^{30}$ Iodine-125 is the most widely used isotope, delivering an apex dose of approximately 69 Gy over 3-4 days. ${ }^{30,58}$ The main disadvantages of this treatment are that it requires two invasive operations to implant and remove the isotope which require hospitalization. ${ }^{42}$ A retrospective study of 36 patients with $\mathrm{CM}^{59}$ revealed that the size of the lesion and subretinal effusion can be shrunk by about $50 \%$. Approximately $58 \%$ of the patients achieved vision improvement or maintained existing vision. The treatment-induced side effects were similar to EBRT, with an incidence of about $8 \%$. However, Wen et al demonstrated that the rate of vision loss after brachytherapy may be up to $26 \%-62 \%,{ }^{60}$ in patients having a history of EBRT or systemic chemotherapy. ${ }^{57}$

\section{Gamma Knife Radiosurgery}

Gamma knife radiosurgery (GKR) is mainly used to treat primary intraocular tumors and has not been widely applied to treat CM. GKR delivers a single dose radiation beam to a well-defined volume, which presents a dramatic dose drop outside the target, thus allowing less radiation damage to the surrounding tissues. ${ }^{61}$ For intraocular metastases, the prescribed dose is approximately $30 \mathrm{~Gy} /$ 10 fractions. The treatment course is shorter than that for EBRT, and is non-invasive. A case series showed that $85 \%$ of patients achieved improvement of ocular symptoms, while $14.3 \%$ experienced vision loss and relapse. In terms of complications, due to the short median followup time of 8 months, only 2 patients complained of cataract $(14.3 \%)$ or eyeball pain $(14.3 \%)$, respectively. Furthermore, GKR may be effective for patients presenting combined cerebral and choroidal metastasis simultaneously. ${ }^{61}$ Due to its improved responses and better compliance, GKR can be used as an alternative treatment to EBRT or brachytherapy. GKR requires precise radiotherapy equipment, which may not be available at all institutions.

\section{Proton Beam Therapy}

Different from other charged particles, the proton conforms to the "Bragg effect". As a non-invasive operation, proton beam therapy (PBT) indications are not limited by metastatic tumor parameters (such as size, location, number of metastases). ${ }^{25}$ The treatment period may be as short as only two fractions. A retrospective cohort ${ }^{62}$ suggested that $84 \%$ of $\mathrm{CM}$ shrunk, $82 \%$ of retinal detachment achieved varying degrees of reattachment, and in $47 \%$ of cases, visual acuity remained similar to baseline. The rate of treatment-induced adverse events was $56 \%$, which was divided into early complications occurring in 1-3 months and late complications 18 months after treatment. The high rate of side effects which may be related to $\mathrm{CM}$ was limited to near the macula and other intraocular functional areas. Thus, PBT may not be fully applicable to tumors close to the visual function area. Moreover, due to the shorter life span of patients with intraocular metastases, long-term side effects are actually rare. ${ }^{63}$ In brief, PBT may be used as a second-line treatment after failure of radiotherapy and chemotherapy. As PBT has not become a popular procedure, the efficacy and complications of intraocular metastases remain to be proven.

Because ocular radiotherapy presents long-term complications and may also lead to vision loss, greater attention should be paid to titrated dosages, especially for those with known high-risk factors.

\section{Other Treatment Modalities}

Photodynamic Therapy

Photodynamic therapy (PDT), an invasive treatment, directly targets the tumor via a non-toxic photosensitizer (the most common is verteporfin) and is activated by light exposure, which generates reactive oxygen species in the tissue microenvironment. ${ }^{30,64}$ Furthermore, verteporfin selectively acts on the tumor vascular endothelial cells to cause intravascular microthrombosis. ${ }^{65}$ Therefore, PDT may not be suitable for tumors adjacent to or partly/completely covering the optic disc. PDT generally requires only one session, which is especially suitable for patients at later disease stages. In addition, there is no need for hospitalization or invasive operations, and the lack of side effects maximizes patient compliance. Conversely, its efficacy is restricted to a certain extent by diameter and thickness of metastases. PDT is more appropriate for tumors located at the posterior equator with mild-tomoderate subretinal effusion, diameter less than $10 \mathrm{~mm}$, and thickness less than $3 \mathrm{~mm} .{ }^{30}$

\section{Transpupillary Thermotherapy}

Transpupillary thermotherapy (TTT) mainly delivers heat to induce tumor necrosis. The parameters of TTT are generally set to a diode infrared laser with a wavelength of $810 \mathrm{~nm}$ to heat to a temperature of $45^{\circ} \mathrm{C}-60^{\circ} \mathrm{C}$, a spot diameter of $1.2 \mathrm{~mm}-3 \mathrm{~mm}, 1$ minute duration, and is repeated weekly. ${ }^{66,67}$ The temperature that produces a subphotocoagulation effect is lower than that of conventional laser treatment, leading to intravascular 
microthrombosis, angiogenesis inhibition, fibrosis, and ultimately tumor necrosis. ${ }^{66,68}$ Among intraocular structures, tissues with high melanin content may achieve a relatively higher treatment efficacy for tumors. ${ }^{69}$ The combination with indocyanine green (ICG) can increase the tumor's response to infrared lasers to improve the treatment effect. ${ }^{70}$ Moreover, the output power of TTT is generally between $150 \mathrm{~mW}-400 \mathrm{~mW}$ according to differences in pigment content of the fundus among races. Lin and Tsai found that TTT combined with intraocular bevacizumab could effectively control isolated small CM $(<10 \mathrm{~mm}$ diameter) from NSCLC and localized subretinal fluid. $^{71}$ Additionally, for multifocal, large $(>15 \mathrm{~mm}$ diameter) CM, with extensive subretinal effusion, TTT is often recommended to be combined with another method, for instance $\mathrm{EBRT}^{72}$ or brachytherapy. ${ }^{73}$ The treatmentinduced adverse events that are often associated with the output power of treatment include: retinal traction, branch retinal vascular occlusion, vitreous and subretinal hemorrhage, and macular or optic disc edema. ${ }^{74}$ In addition, Wang et al documented that multiple subthresholds (biomicroscopically invisible laser effect) are effective to treat $\mathrm{CM}$, even if the tumor locates near the macula, its efficacy and safety can be guaranteed. ${ }^{66}$

\section{Intravitreal Bevacizumab}

Molecular targeting agents (such as bevacizumab) that inhibit tumor angiogenesis are suitable for managing metastases that occur through the hematogenous route. Intravitreal administration of bevacizumab (IV-Bev) achieves promising effects on tumor shrinking, absorbing exudative subretinal fluid and relieving clinical symptoms that have been observed in CM from lung cancer. IV-Bev is not limited by the location, size, or number of tumors, and can also be utilized repeatedly. Further, IV-Bev can also be used as second-line treatment for $\mathrm{CM}$ that has failed systemic chemotherapy, or may be considered as an alternative choice for patients unwilling to receive radiotherapy or chemotherapy. ${ }^{75}$ There is no standard dose for treatment of intraocular metastases. Reviews indicate that in most cases, the chosen dose ranged from 1.25 to $4.0 \mathrm{mg}$ to treat $\mathrm{CM} .^{45,76,77}$ Furthermore, there are also reports of failures with IV-Bev. ${ }^{78}$ Lin et $\mathrm{al}^{79}$ speculated that the subretinal fluid might act as a barrier to block absorption of bevacizumab by the choroid and reduce drug concentration, which is however inconsistent with successful cases of resolved subretinal effusion. As IV-Bev is still an experimental alternative for $\mathrm{CM}$, the current clinical experience cannot fully explain nor prove therapeutic effects on CM. Which type of patient would benefit from IV-Bev and when to use needs to be further investigated.

\section{Surgery}

Notably, although most patients with multiple metastases may not be suited for intervention, resection of the primary lesion can be selectively performed on consultation with a multidisciplinary team, ${ }^{35}$ which will help to define diagnosis and minimize tumor-related symptoms.

Eyeball surgery carries a high risk of potential morbidity and often there is no benefit for tumor debulking. Only one case has been reported showing successful outcome of transscleral local resection of a large choroidal metastasis from primary pulmonary leiomyosarcoma. ${ }^{80}$ As surgery may greatly affect the patient's quality of life, it is only used for patients whose tumor shows insensitivity to radiotherapy or in cases of glaucoma after radiotherapy, or in those experiencing severe ocular symptoms. Therefore, enucleation is not a routine recommendation.

However, in cases in which it is difficult to obtain a pathological diagnosis for the tumor, enucleation or fine needle aspiration biopsy (FNAB) transsclerally or transvitreally could not only contribute to making a clear pathological diagnosis, but it may also provide information relative to possible gene mutational status, to guide accurate treatment strategies.

\section{Combination of Systemic Therapy with Local Treatment}

In stage IV NSCLC, surgical resection of the primary tumor or local treatment, in combination with systemic therapy alone, may provide a survival benefit for selected patients. In particular, EBRT becomes an effective treatment option for a subset of patients who are not candidates for surgical resection. ${ }^{81}$ Generally, for intraocular metastasis, systemic therapy seems to have a lower local disease control rate (DCR) and a higher local recurrence rate when compared with local treatment. Intervention using local treatments helps to achieve higher response rates, while possibly also increasing local treatment-related complications. To compare the effects of systemic treatment alone and its combination with local treatment, a retrospective study including 194 patients with intraocular metastases was conducted. The study showed that patients achieving a partial response comprised $68 \%$ in the systemic treatment group versus $82 \%-86 \%$ in the combination treatment group, and the recurrence rate after 1 year was $32 \%$ in the 
systemic treatment group versus $14 \%-18 \%$ in the combination group. ${ }^{17}$

Of note, for patients acquiring local or systemic resistance after treatment with TKIs, local treatment should be considered in those presenting progression of $\mathrm{CM}$ or deterioration of ocular symptoms. The practice of ocular treatment being administered simultaneously with systemic treatment to achieve a better systemic and local control still needs further clinical studies to determine its safety and efficacy.

\section{Therapeutic Options for Concurrent Brain Metastases}

Approximately $22 \%-32.5 \%$ of lung adenocarcinoma patients with $\mathrm{CM}$ simultaneously metastasize to the brain. ${ }^{20,21}$ Riess et al found that a minority of patients concurrently presenting choroidal and brain metastases may eventually relapse in the form of leptomeningeal metastasis. ${ }^{40}$ Thus, formulating treatment strategies for this population subset is challenging. For patients harboring negative driver genes, the therapeutic strategies are mainly systemic chemotherapy, anti- angiogenetic therapy, or immunotherapy, with or without local radiotherapy. Although clinical trials and experience indicate that chemotherapy and bevacizumab might effectively control CM or brain metastasis, whether these approaches could simultaneously control intraocular and intracranial metastases remains unconfirmed. ${ }^{82,83}$

Conventionally, brain radiotherapy is standard treatment for intracranial metastases. Similar to brain metastases, EBRT is also traditional treatment for CM. For patients who concomitantly present brain metastases and $\mathrm{CM}$, whole brain radiation therapy (WBRT) may be considered to encompass the posterior orbit and choroid, ${ }^{30}$ and therefore prevent repeated exposure of normal brain tissues to radiation, and to reduce the risk of development of brain metastases. For most patients with multi-metastatic disease, systemic treatment is needed. However, for individuals with metachronous intracranial or intraocular lesions, whether brain and ocular radiotherapy should be applied concurrently is still unclear. Multiple complex factors should be taken into consideration.

Preclinical data and clinical trials have revealed that the new-generation of EGFR or ALK TKIs present higher central permeability, which can significantly ameliorate the local tumor control rate and markedly improve PFS of brain metastases. ${ }^{84-86}$ Therefore, for patients with concomitant $\mathrm{CM}$ and brain metastases, a new generation of TKIs is preferred. ${ }^{87}$ Due to limited experience, the effectiveness of this therapeutic modality needs to be further confirmed.

Figure 2 summarizes the local treatment algorithm for $\mathrm{CM}$.

\section{Prospects of Immunotherapy in Choroidal Metastasis}

To date, experience with immunotherapy for CM has been limited, only a few reports on uveal melanoma treated with immune checkpoint inhibitors (ICIs) have been published. The clinical efficacy of ICIs in uveal melanoma is unfavorable. ${ }^{88}$ Occasional responses have been observed in some retrospective case series evaluating anti-PD-1/ anti-PD-L1 agents, which suggest that ICIs may benefit a small subset of patients. ${ }^{89,90}$ This discrepancy may be explained by different reasons. First, the eye is an immune privileged organ that prevents inflammation by secreting several immunosuppressive factors, such as transforming growth factor-beta (TGF- $\beta$ ), $\alpha$-melanocyte-stimulating hormone $(\alpha-\mathrm{MSH})$, calcitonin gene-related peptide (CGRP), vasoactive intestinal protein (VIP), and indoleamine 2,3 dioxygenase (IDO). ${ }^{91}$ Moreover, the cornea, iris, and retina cells express immunosuppressive ligands, such as PD-L1 and FasL on their surface, ${ }^{92}$ inducing immune tolerance by programming monocytes and $\mathrm{T}$ cells, and triggering checkpoints. ${ }^{93}$ When antigens enter the eye, a unique mechanism of immune privilege known as "anterior chamber-associated immune deviation" (ACAID) is involved in the immunomodulatory phenomenon. ${ }^{94}$ Second, a physical barrier known as the blood-retinal barrier (BRB) that forms tight junctions between endothelial cells, and the retinal pigment epithelium (RPE) cell monolayer could inhibit migration of immune cells from the circulation into the eye. ${ }^{95}$ In addition, the current clinical evidence indicating immunotherapy for intraocular metastases is inadequate thus, expectations on whether ICIs are effective for $\mathrm{CM}$ should be devised. In clinical practice, selected patients may be treated with ICIs and ongoing clinical trials should be prioritized in such patients. Additionally, other novel immunologic therapeutic strategies should be investigated in this population.

\section{Conclusion}

The lung is the second most common primary site of $\mathrm{CM}$, and up to one-third of patients present intraocular symptoms as the primary clinical manifestation. Eye examinations and extensive investigations should be performed to identify primary 


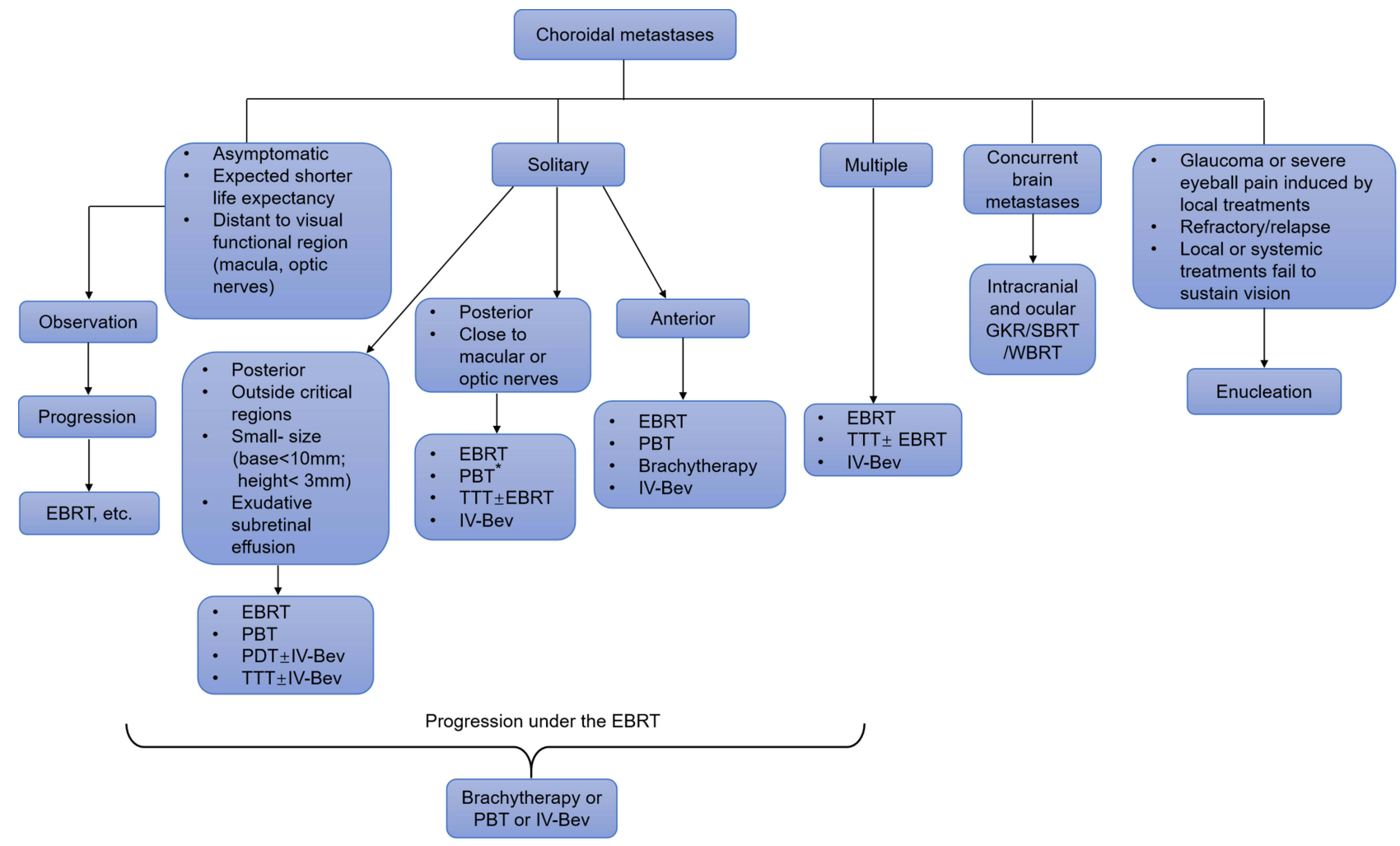

Figure 2 The local treatment algorithm for CM. *In patients with tumors close to the macula, PBT should be administered at smaller doses, which can be achieved by dose division and contributes to the protection of surrounding normal tissue.

Abbreviations: EBRT, external beam radiation therapy; GKR, gamma knife radiosurgery; IV-Bev, intravitreal bevacizumab; PBT, proton beam therapy; PDT, photodynamic therapy; SBRT, stereotactic body radiation therapy; TTT, transpupillary thermotherapy; WBRT, whole-brain radiation therapy.

malignancy, while pathological examination of ocular biopsy could be performed to differentiate diagnosis if necessary.

The purpose of treatment is to improve quality of life and prolong survival. This review introduces the indications, and advantages and disadvantages of various treatment options for the disease. Systemic chemotherapy has an unfavorable systemic DCR. TKIs should be administered for patients harboring oncologic driver genes as the first-line choice. The evidence supporting ICIs for treatment of intraocular metastases is limited, and corresponding clinical studies are warranted. EBRT is a traditional treatment modality with remarkable efficacy. PDT, TTT, GKR, and IV-Bev represent local treatment options also are effective for intraocular metastases and can be used as alternatives for EBRT or as second-line treatment. Resection of primary malignancy or eyeball removal is exclusively performed in those with difficult diagnostic situations and severe clinical symptoms.

For patients with $\mathrm{CM}$ synchronous or metachronous brain metastases, the initial timing and sequence of systemic and local treatments remain controversial and need to be further investigated in the future.
Nonetheless, the level of proof about current therapies in clinical practice is insufficient. Further clinical studies are warranted to investigate the advantages and disadvantages of different treatment modalities.

\section{Acknowledgments}

Editorial assistance in the preparation of this article was provided by The Charlesworth Group for the expert linguistic services.

\section{Disclosure}

The authors report no conflicts of interest in this work.

\section{References}

1. Konstantinidis L, Damato B. Intraocular metastases - a review. Asia Pac J Ophthalmol. 2017;6(2):208-214.

2. Shields CL, Shields JA, Gross NE, Schwartz GP, Lally SE. Survey of 520 eyes with uveal metastases. Ophthalmology. 1997;104 (8):1265-1276. doi:10.1016/S0161-6420(97)30148-1

3. Albert DM, Zimmermann AW Jr., Zeidman I. Tumor metastasis to the eye. 3. The fate of circulating tumor cells to the eye. Am J Ophthalmol. 1967;63(4):733-738. doi:10.1016/0002-9394(67)91299-8 
4. Freedman MI, Folk JC. Metastatic tumors to the eye and orbit. Patient survival and clinical characteristics. Arch Ophthalmol. 1987;105(9):1215-1219. doi:10.1001/archopht.1987.01060090 073031

5. Kreusel KM, Bechrakis NE, Wiegel T, Krause L, Foerster MH. Incidence and clinical characteristics of symptomatic choroidal metastasis from lung cancer. Acta Ophthalmol. 2008;86 (5):515-519. doi:10.1111/j.1600-0420.2007.01081.x

6. Harbour JW, De Potter P, Shields CL, Shields JA. Uveal metastasis from carcinoid tumor. Clinical observations in nine cases. Ophthalmology. 1994;101(6):1084-1090. doi:10.1016/S01616420(94)38030-4

7. Paget S. The distribution of secondary growths in cancer of the breast. 1889. Cancer Metastasis Rev. 1989;8(2):98-101.

8. Weiss L. Comments on hematogenous metastatic patterns in humans as revealed by autopsy. Clin Exp Metastasis. 1992;10 (3):191-199. doi:10.1007/BF00132751

9. Duke-Elder S. Diseases of the uveal tract: muscular tumours: leiomyoma. Syst Ophthalmol. 1966;10:799-805.

10. Ferry AP, Font RL. Carcinoma metastatic to the eye and orbit. I. A clinicopathologic study of 227 cases. Arch Ophthalmol. 1974;92(4):276-286. doi:10.1001/archopht.1974.01010010286003

11. Stephens RF, Shields JA. Diagnosis and management of cancer metastatic to the uvea: a study of 70 cases. Ophthalmology. 1979;86(7):1336-1349. doi:10.1016/S0161-6420(79)35393-3

12. Mewis L, Young SE. Breast carcinoma metastatic to the choroid. Analysis of 67 patients. Ophthalmology. 1982;89(2):147-151. doi:10.1016/S0161-6420(82)34838-1

13. Bloch RS, Gartner S. The incidence of ocular metastatic carcinoma. Arch Ophthalmol. 1971;85(6):673-675. doi:10.1001/ archopht.1971.00990050675005

14. Jardel P, Sauerwein W, Olivier T, et al. Management of choroidal metastases. Cancer Treat Rev. 2014;40(10):1119-1128. doi:10.10 16/j.ctrv.2014.09.006

15. $\mathrm{Xu} \mathrm{Y,} \mathrm{Sun} \mathrm{Y,} \mathrm{Zhao} \mathrm{J,} \mathrm{et} \mathrm{al.} \mathrm{[Ocular} \mathrm{metastasis} \mathrm{in} \mathrm{lung} \mathrm{cancer:}$ a retrospective analysis in a single Chinese hospital and literature review]. Zhongguo Fei Ai Za Zhi. 2017;20(5):326-333. Chinese.

16. Jianhua D. Current status and research progress of CM of lung cancer in China. Chin J Thorac Cardiovasc Surg. 2018;34 (12):754-759.

17. Shah SU, Mashayekhi A, Shields CL, et al. Uveal metastasis from lung cancer: clinical features, treatment, and outcome in 194 patients. Ophthalmology. 2014;121(1):352-357. doi:10.1016/j. ophtha.2013.07.014

18. Demirci H, Shields CL, Chao AN, Shields JA. Uveal metastasis from breast cancer in 264 patients. Am J Ophthalmol. 2003;136 (2):264-271. doi:10.1016/S0002-9394(03)00192-2

19. Kanthan GL, Jayamohan J, Yip D, Conway RM. Management of metastatic carcinoma of the uveal tract: an evidence-based analysis. Clin Exp Ophthalmol. 2007;35(6):553-565. doi:10.11 11/j.1442-9071.2007.01550.x

20. Amer R, Pe'er J, Chowers I, Anteby I. Treatment options in the management of choroidal metastases. Ophthalmologica. 2004;218 (6):372-377. doi:10.1159/000080939

21. Asteriou C, Konstantinou D, Kleontas A, et al. Blurred vision due to choroidal metastasis as the first manifestation of lung cancer: a case report. World J Surg Oncol. 2010;8:2. doi:10.1186/14777819-8-2

22. Wiegel T, Kreusel KM, Bornfeld N, et al. Frequency of asymptomatic choroidal metastasis in patients with disseminated breast cancer: results of a prospective screening programme. $\mathrm{Br}$ J Ophthalmol. 1998;82(10):1159-1161. doi:10.1136/bjo.82.10.1159

23. Kreusel KM, Wiegel T, Stange M, Bornfeld N, Hinkelbein W, Foerster $\mathrm{MH}$. Choroidal metastasis in disseminated lung cancer: frequency and risk factors. Am J Ophthalmol. 2002;134 (3):445-447. doi:10.1016/S0002-9394(02)01580-5
24. Yang CJ, Tsai YM, Tsai MJ, Chang HL, Huang MS. The effect of chemotherapy with cisplatin and pemetrexed for choroidal metastasis of non-squamous cell carcinoma. Cancer Chemother Pharmacol. 2014;73(1):199-205. doi:10.1007/s00280-0132341-4

25. Paul Chan RV, Young LH. Treatment options for metastatic tumors to the choroid. Semin Ophthalmol. 2005;20(4):207-216. doi:10.1080/08820530500350589

26. Konstantinidis L, Rospond-Kubiak I, Zeolite I, et al. Management of patients with uveal metastases at the Liverpool Ocular Oncology Centre. $\mathrm{Br} \quad J$ Ophthalmol. 2014;98(1):92-98. doi:10.1136/bjophthalmol-2013-303519

27. Arepalli S, Kaliki S, Shields CL. Choroidal metastases: origin, features, and therapy. Indian J Ophthalmol. 2015;63(2):122-127. doi:10.4103/0301-4738.154380

28. Cohen VM. Ocular metastases. Eye (Lond). 2013;27(2):137-141. doi:10.1038/eye.2012.252

29. Lu S, Azada MC, Ou SH. Choroidal metastasis response to crizotinib in a ROS1-rearranged NSCLC patient. Lung Cancer. 2015;87(2):207-209. doi:10.1016/j.lungcan.2014.12.011

30. Mathis T, Jardel P, Loria O, et al. New concepts in the diagnosis and management of choroidal metastases. Prog Retin Eye Res. 2019;68:144-176.

31. Smith JA, Gragoudas ES, Dreyer EB. Uveal metastases. Int Ophthalmol Clin. 1997;37(4):183-199. doi:10.1097/0000 4397-199703740-00016

32. Shimomura I, Tada Y, Miura G, et al. Choroidal metastasis of non-small cell lung cancer that responded to gefitinib. Case Rep Ophthalmol Med. 2013;2013:213124.

33. Singh A, Singh P, Sahni K, Shukla P, Shukla V, Pant NK. Nonsmall cell lung cancer presenting with choroidal metastasis as first sign and showing good response to chemotherapy alone: a case report. J Med Case Rep. 2010;4:185. doi:10.1186/1752-19474-185

34. George B, Wirostko WJ, Connor TB, Choong NW. Complete and durable response of choroid metastasis from non-small cell lung cancer with systemic bevacizumab and chemotherapy. $J$ Thorac Oncol. 2009;4(5):661-662. doi:10.1097/JTO.0b013e31819c9a73

35. Guo Y, Wang X, Xiao J, et al. Lung squamous cell carcinoma with solitary ocular metastasis and its successful treatment with thoracic surgery and chemotherapy: an interesting and rare case report. BMC Cancer. 2018;18(1):1004. doi:10.1186/s12885-018-4944-y

36. Makabe K, Kurishima K, Shiozawa T, et al. Treatment of choroid metastasis from lung adenocarcinoma with bevacizumab-containing chemotherapy: a case report. Exp Ther Med. 2016;11(1):239-242. doi:10.3892/etm.2015.2893

37. Maskell D, Geropantas K, Kouroupis M, Glenn A, Ajithkumar T. Treatment of choice for patients with EGFR mutation-positive non-small cell lung carcinoma presenting with choroidal metastases: radiotherapy or TKIs? Can J Ophthalmol. 2017;52(1):e22e25. doi:10.1016/j.jcjo.2016.09.010

38. Wharam M, Schachat AP. Choroidal Metastasis. Retina Fifth Edition. 2006;3:811-818.doi:10.1016/B978-0-323-02598-0.50051-3

39. Hussain Z, Khan J, Ali S. Impact of therapy \& age in choroidal cancers: a retrospective cohort analysis of 7722 patients from a US national database. Clin Ophthalmol. 2021;15:1763-1774. doi:10.2147/OPTH.S298700

40. Riess JW, Nagpal S, Das M, Neal JW, Kim JW, Wakelee HA. A case series of NSCLC patients with different molecular characteristics and choroidal metastases: improvement in vision with treatment including pemetrexed and bevacizumab. $J$ Thorac Oncol. 2013;8(2):e17-18. doi:10.1097/JTO.0b013e31827690da

41. Kourie HR, Antoun J, Schakal A, Nasr E, Sahyoun M, Kattan J. Complete disappearance of choroidal metastasis from lung adenocarcinoma treated with bevacizumab and chemotherapy. Case Rep Ophthalmol Med. 2015;2015:142408. 
42. Chen CJ, McCoy AN, Brahmer J, Handa JT. Emerging treatments for choroidal metastases. Surv Ophthalmol. 2011;56(6):511-521. doi:10.1016/j.survophthal.2011.05.001

43. Shultz DB, Filippi AR, Thariat J, Mornex F, Loo BW Jr., Ricardi U. Stereotactic ablative radiotherapy for pulmonary oligometastases and oligometastatic lung cancer. $J$ Thorac Oncol. 2014;9(10):1426-1433. doi:10.1097/JTO.0000000000000317

44. Ashworth A, Rodrigues G, Boldt G, Palma D. Is there an oligometastatic state in non-small cell lung cancer? A systematic review of the literature. Lung Cancer. 2013;82(2):197-203. doi:10.1016/j.lungcan.2013.07.026

45. Maturu VN, Singh N, Bansal P, et al. Combination of intravitreal bevacizumab and systemic therapy for choroidal metastases from lung cancer: report of two cases and a systematic review of literature. Med Oncol. 2014;31(4):901. doi:10.1007/s12032-014-0901-z

46. Kim SW, Kim MJ, Huh K, Oh J. Complete regression of choroidal metastasis secondary to non-small-cell lung cancer with intravitreal bevacizumab and oral erlotinib combination therapy. Ophthalmologica. 2009;223(6):411-413. doi:10.1159/000229307

47. Petit AM, Rak J, Hung MC, et al. Neutralizing antibodies against epidermal growth factor and ErbB-2/neu receptor tyrosine kinases down-regulate vascular endothelial growth factor production by tumor cells in vitro and in vivo: angiogenic implications for signal transduction therapy of solid tumors. Am J Pathol. 1997;151(6):1523-1530.

48. Ciardiello F, Caputo R, Damiano V, et al. Antitumor effects of ZD6474, a small molecule vascular endothelial growth factor receptor tyrosine kinase inhibitor, with additional activity against epidermal growth factor receptor tyrosine kinase. Clin Cancer Res. 2003;9(4):1546-1556.

49. Funazo T, Morita K, Ikegami N, et al. Successful treatment with alectinib for choroidal metastasis in anaplastic lymphoma kinase rearranged non-small cell lung cancer. Intern Med. 2017;56 (17):2317-2320. doi:10.2169/internalmedicine.8488-16

50. Mariachiara M, Celeste R, Federico F, Nicole B, Antonio C. Choroidal metastasis from non-small-cell lung cancer responsive to Osimertinib: a case report: efficacy of a third-generation epidermal growth factor tyrosine kinase inhibitor. Int Ophthalmol. 2018;38(6):2669-2675. doi:10.1007/s10792-017-0749-2

51. Ye X, Kaliki S, Shields CL. Rapid regression of choroidal metastasis from lung cancer using erlotinib (Tarceva). Oman J Ophthalmol. 2014;7(2):75-77. doi:10.4103/0974-620X.137159

52. Hida T, Nokihara H, Kondo M, et al. Alectinib versus crizotinib in patients with ALK-positive non-small-cell lung cancer (J-ALEX): an open-label, randomised Phase 3 trial. Lancet. 2017;390(10089):29-39. doi:10.1016/S0140-6736(17)30565-2

53. Rudoler SB, Corn BW, Shields CL, et al. External beam irradiation for choroid metastases: identification of factors predisposing to long-term sequelae. Int J Radiat Oncol Biol Phys. 1997;38 (2):251-256. doi:10.1016/S0360-3016(97)00050-3

54. Rudoler SB, Shields CL, Corn BW, et al. Functional vision is improved in the majority of patients treated with external-beam radiotherapy for choroid metastases: a multivariate analysis of 188 patients. J Clin Oncol. 1997;15(3):1244-1251. doi:10.1200/ JCO.1997.15.3.1244

55. Rosset A, Zografos L, Coucke P, Monney M, Mirimanoff RO. Radiotherapy of choroidal metastases. Radiother Oncol. 1998;46 (3):263-268. doi:10.1016/S0167-8140(97)00209-0

56. Wiegel T, Bottke D, Kreusel KM, et al. External beam radiotherapy of choroidal metastases - final results of a prospective study of the German Cancer Society (ARO 95-08). Radiother Oncol. 2002;64(1):13-18. doi:10.1016/S0167-8140(02)00134-2

57. Shields CL. Plaque radiotherapy for the management of uveal metastasis. Curr Opin Ophthalmol. 1998;9(3):31-37. doi:10.10 97/00055735-199806000-00006
58. Echegaray JJ, Bechrakis NE, Singh N, Bellerive C, Singh AD Iodine-125 brachytherapy for uveal melanoma: a systematic review of radiation dose. Ocul Oncol Pathol. 2017;3 (3):193-198. doi:10.1159/000455872

59. Shields CL, Shields JA, De Potter P, et al. Plaque radiotherapy for the management of uveal metastasis. Arch Ophthalmol. 1997;115 (2):203-209. doi:10.1001/archopht.1997.01100150205010

60. Wen JC, Oliver SC, McCannel TA. Ocular complications following I-125 brachytherapy for choroidal melanoma. Eye (Lond). 2009;23(6):1254-1268. doi:10.1038/eye.2009.43

61. Cho KR, Lee KM, Han G, Kang SW, Lee JI. Gamma knife radiosurgery for cancer metastasized to the ocular choroid. $J$ Korean Neurosurg Soc. 2018;61(1):60-65. doi:10.3340/ jkns.2016.0606.003

62. Tsina EK, Lane AM, Zacks DN, Munzenrider JE, Collier JM, Gragoudas ES. Treatment of metastatic tumors of the choroid with proton beam irradiation. Ophthalmology. 2005;112 (2):337-343. doi:10.1016/j.ophtha.2004.09.013

63. Gragoudas ES, Goitein M, Verhey L, Munzenreider J, Suit HD, Koehler A. Proton beam irradiation. An alternative to enucleation for intraocular melanomas. Ophthalmology. 1980;87(6):571-581. doi:10.1016/S0161-6420(80)35212-3

64. Harbour JW. Photodynamic therapy for choroidal metastasis from carcinoid tumor. Am J Ophthalmol. 2004;137(6):1143-1145. doi:10.1016/j.ajo.2004.01.009

65. Kaliki S, Shields CL, Al-Dahmash SA, Mashayekhi A, Shields JA. Photodynamic therapy for choroidal metastasis in 8 cases. Ophthalmology. 2012;119(6):1218-1222. doi:10.1016/j. ophtha.2011.12.024

66. Wang TJ, Chen MS, Yang CM, Ho TC. Subthreshold transpupillary thermotherapy for early resolution of foveal subretinal fluid in choroidal metastasis. Retina. 2006;26(4):391-395. doi:10.10 97/01.iae.0000238547.89873.2f

67. Li T. Overview of research on transpupillary thermotherapy for choroidal melanoma. Chin J Ocul Fundus Dis. 2001;17(4):327329.

68. Kiratli H, Bilgic S. Solitary choroidal metastasis managed by transpupillary thermotherapy. Eye (Lond). 2000;14(Pt 5):799-800. doi:10.1038/eye.2000.215

69. Oosterhuis JA, Journée-de Korver HG, Keunen JE. Transpupillary thermotherapy: results in 50 patients with choroidal melanoma. Arch Ophthalmol. 1998;116(2):157-162. doi:10.1001/archopht.116.2.157

70. Chong LP, Ozler SA, de Queiroz JM Jr., Liggett PE. Indocyanine green-enhanced diode laser treatment of melanoma in a rabbit model. Retina. 1993;13(3):251-259. doi:10.1097/00006982-1993 13030-00012

71. Lin CJ, Tsai YY. The effect of intravitreal bevacizumab and transpupillary thermotherapy on choroidal metastases and literature review. Indian J Ophthalmol. 2015;63(1):37-41. doi:10. 4103/0301-4738.151465

72. Kiratli H, Bilgic S. Transpupillary thermotherapy in the management of choroidal metastases. Eur J Ophthalmol. 2004;14 (5):423-429. doi:10.1177/112067210401400510

73. Vianna RN, Pena R, Muralha A, Muralha L, Muranaka E. Transpupillary thermotherapy in the treatment of choroidal metastasis from breast carcinoma. Int Ophthalmol. 2004;25(1):23-26. doi:10.1023/B:INTE.0000018525.92811.e4

74. Parrozzani R, Boccassini B, De Belvis V, Radin PP, Midena E. Long-term outcome of transpupillary thermotherapy as primary treatment of selected choroidal melanoma Acta Ophthalmol. 2009;87(7):789-792. doi:10.1111/j.17553768.2008.01327.x

75. Kim M, Kim CH, Koh HJ, Lee SC, Kim SS. Intravitreal bevacizumab for the treatment of choroidal metastasis. Acta Ophthalmol. 2014;92(1):e80-82. doi:10.1111/aos.12285 
76. Lai CL, Fan KS, Lee YH, Chen HC, Fan WH. Intravitreal administration of bevacizumab in the treatment of choroidal metastasis in a patient with erlotinib-failed pulmonary adenocarcinoma. Lung Cancer. 2012;76(3):496-498. doi:10.10 16/j.lungcan.2012.02.020

77. Amselem L, Cervera E, Diaz-Llopis M, et al. Intravitreal bevacizumab (Avastin) for choroidal metastasis secondary to breast carcinoma: short-term follow-up. Eye (Lond). 2007;21 (4):566-567. doi:10.1038/sj.eye.6702647

78. Maudgil A, Sears KS, Rundle PA, Rennie IG, Salvi SM. Failure of intravitreal bevacizumab in the treatment of choroidal metastasis. Eye (Lond). 2015;29(5):707-711. doi:10.1038/ eye. 2015.21

79. Lin CJ, Li KH, Hwang JF, Chen SN. The effect of intravitreal bevacizumab treatment on choroidal metastasis of colon adenocarcinoma - case report. Eye (Lond). 2010;24(6):1102-1103. doi:10.1038/eye.2009.257

80. Anderson MF, Coupland SE, Bissett D, Atta H, Damato BE. Choroidal metastasis from primary pulmonary leiomyosarcoma. Clin Exp Ophthalmol. 2011;39(7):705-707. doi:10.1111/j.14429071.2011.02528.x

81. Uhlig J, Case MD, Blasberg JD, et al. Comparison of survival rates after a combination of local treatment and systemic therapy vs systemic therapy alone for treatment of stage IV Non-small cell lung cancer. JAMA Netw Open. 2019;2(8):e199702. doi:10.1001/jamanetworkopen.2019.9702

82. Bearz A, Garassino I, Tiseo M, et al. Activity of pemetrexed on brain metastases from non-small cell lung cancer. Lung Cancer. 2010;68(2):264-268. doi:10.1016/j.lungcan.2009.06.018

83. Besse B, Le Moulec S, Mazieres J, et al. Bevacizumab in patients with nonsquamous non-small cell lung cancer and asymptomatic, untreated brain metastases (BRAIN): a nonrandomized, phase II study. Clin Cancer Res. 2015;21(8):1896-1903. doi:10.1158/ 1078-0432.CCR-14-2082

84. Reungwetwattana $\mathrm{T}$, Nakagawa $\mathrm{K}$, Cho $\mathrm{BC}$, et al. CNS response to osimertinib versus standard epidermal growth factor receptor tyrosine kinase inhibitors in patients with untreated EGFR-mutated advanced non-small-cell lung cancer. $J$ Clin Oncol. 2018;36:3290.

85. Peters S, Camidge DR, Shaw AT, et al. Alectinib versus crizotinib in untreated ALK-positive non-small-cell lung cancer. $N$ Engl J Med. 2017;377(9):829-838. doi:10.1056/NEJMoa1704795

86. Shaw AT, Felip E, Bauer TM, et al. Lorlatinib in non-small-cell lung cancer with ALK or ROS1 rearrangement: an international, multicentre, open-label, single-arm first-in-man Phase 1 trial. Lancet Oncol. 2017;18(12):1590-1599. doi:10.1016/S14702045(17)30680-0

87. Sheils CR, Hartmann A, Kuriyan AE. Visual disturbance in a middle-aged woman with non-small cell lung cancer. JAMA Ophthalmol. 2018;136(6):702-703. doi:10.1001/jamaophthalmol. 2017.5776

88. Komatsubara KM, Carvajal RD. Immunotherapy for the treatment of uveal melanoma: current status and emerging therapies. Curr Oncol Rep. 2017;19(7):45. doi:10.1007/s11912-017-0606-5

89. Fernandez-Diaz AB, Garcia-Medina A, Ferrer-Guillen B, Berrocal A. Eye immune privilege? Nivolumab plus ipilimumab: successful treatment in a patient with cutaneous melanoma and ocular metastases. Melanoma Res. 2019;29(3):345-347. doi:10. 1097/CMR.0000000000000591

90. Morkos M, Jain P, Pavlick AC, Finger PT. Ipsilateral metastatic choroidal melanoma responds to systemic immunotherapy. Eur $J$ Ophthalmol. 2020;30(5):NP69-NP73. doi:10.1177/1120672 119839925

91. Rossi E, Schinzari G, Zizzari IG, et al. Immunological backbone of uveal melanoma: is there a rationale for immunotherapy? Cancers. 2019;11(8):1055. doi:10.3390/cancers 11081055
92. Niederkorn JY. Immune escape mechanisms of intraocular tumors. Prog Retin Eye Res. 2009;28(5):329-347. doi:10.1016/j. preteyeres.2009.06.002

93. Taylor AW, Ng TF. Negative regulators that mediate ocular immune privilege. J Leukoc Biol. 2018;103(6):1179-1187. doi:10.1002/JLB.3MIR0817-337R

94. Stein-Streilein J, Streilein JW. Anterior chamber associated immune deviation (ACAID): regulation, biological relevance, and implications for therapy. Int Rev Immunol. 2002;21(23):123-152. doi:10.1080/08830180212066

95. Zhou R, Horai R, Silver PB, et al. The living eye "disarms" uncommitted autoreactive $\mathrm{T}$ cells by converting them to Foxp3(+) regulatory cells following local antigen recognition. J Immunol. 2012;188 (4):1742-1750. doi:10.4049/jimmunol.1102415

96. Sobottka B, Schlote T, Krumpaszky HG, Kreissig I. Choroidal metastases and choroidal melanomas: comparison of ultrasonographic findings. Br J Ophthalmol. 1998;82(2):159. doi:10.1136/ bjo.82.2.159

97. Guan LN, Liu M-Y, Zhang WW. Clinical imaging analysis of choroidal melanoma and choroidal metastatic oarcinoma. J Harbin Med Univ. 2009;43(2):154-157.

98. Coleman DJ, Abramson DH, Jack RL, Franzen LA. Ultrasonic diagnosis of tumors of the choroid. Arch Ophthalmol. 1974;91 (5):344-354. doi:10.1001/archopht.1974.03900060356002

99. Peddada K, Dalvin LA, Mashayekhi A, Shields CL. Diagnostic challenges in necrotic uveal melanoma. Retin Cases Brief Rep. 2019. doi:10.1097/ICB.0000000000000913

100. Yu Y, Cai G, Feng Cui, et al. Fundus fluorescence angiography and indocyanine green angiography in choroidal melanoma 5 case. Chin J Ophthalmol. 2003;39(2):112-114.

101. Guo P, Wang Y, Ma G, Cui Y. The diagnostic value of contrast-enhanced ultrasound combined with fluorescein angiography in choroidal tumors. J Clin Ultrasound Med. 2016;18(10):662-666.

102. Al-Dahmash SA, Shields CL, Kaliki S, Johnson T, Shields JA. Enhanced depth imaging optical coherence tomography of choroidal metastasis in 14 eyes. Retina. 2014;34(8):1588-1593. doi:10.1097/IAE.0000000000000131

103. Mrejen S, Spaide RF. Optical coherence tomography: imaging of the choroid and beyond. Surv Ophthalmol. 2013;58(5):387-429. doi:10.1016/j.survophthal.2012.12.001

104. Arevalo JF, Fernandez CF, Garcia RA. Optical coherence tomography characteristics of choroidal metastasis. Ophthalmology. 2005;112(9):1612-1619. doi:10.1016/j. ophtha.2005.03.030

105. Zhang J, Li H, Jiao K, Zhang L, Li J. Characteristic analysis for optical coherence tomography images of choroidal neoplasms. Recent Adv Ophthalmol. 2020;40(4):353-356.

106. Cennamo G, Romano MR, Breve MA, et al. Evaluation of choroidal tumors with optical coherence tomography: enhanced depth imaging and OCT-angiography features. Eye (Lond). 2017;31 (6):906-915. doi:10.1038/eye.2017.14

107. Peyster RG, Augsburger JJ, Shields JA, Hershey BL, Eagle R Jr., Haskin ME. Intraocular tumors: evaluation with MR imaging. Radiology. 1988;168(3):773-779. doi:10.1148/radiology.168.3. 3406407

108. Lin R-J, Huang Y-Y. Diagnostic imaging of choroidal malignant melanoma. Heilongjiang Med J. 2018;42(1).URL:http://qikan. cqvip.com/Qikan/Article/Detail?id=675013367

109. Michelson JB, Felberg NT, Shields JA. Carcinoembryonic antigen. Its role in the evaluation of intraocular malignant tumors. Arch Ophthalmol. 1976;94(3):414-416. doi:10.1001/archopht.19 76.03910030200005

110. Michelson JB, Felberg NT, Shields JA. Evaluation of metastatic cancer to the eye. Carcinoembryonic antigen and gamma glutamyl transpeptidase. Arch Ophthalmol. 1977;95(4):692-694. doi:10.1001/archopht.1977.04450040158025 
111. Bandyopadhyay S, Adrean SD, Puklin JE, Feng J. Choroidal metastasis from an occult primary diagnosed by fine-needle aspiration: a case report. Diagn Cytopathol. 2009;37(1):38-41. doi:10.1002/dc.20918

112. Biswas J, Kabra S, Krishnakumar S, Shanmugam MP. Clinical and histopathological characteristics of uveal melanoma in Asian Indians. A study of 103 patients. Indian J Ophthalmol. 2004;52 (1):41-44.
113. Chao Pei J-XL. Research progress on choroidal melanoma. Int J Ophthalmol. 2017;17(12):2256-2259.

114. Li L, Wang WJ, Chen RJ. Fundus fluorescein angiography in metastatic choroidal carcinomas and differentiating metastatic choroidal carcinomas from primary choroidal melanomas. Chin J Ophthalmol. 2011;47(1):27-34.

\section{Publish your work in this journal}

OncoTargets and Therapy is an international, peer-reviewed, open access journal focusing on the pathological basis of all cancers, potential targets for therapy and treatment protocols employed to improve the management of cancer patients. The journal also focuses on the impact of management programs and new therapeutic

Submit your manuscript here: https://www.dovepress.com/oncotargets-and-therapy-journal agents and protocols on patient perspectives such as quality of life, adherence and satisfaction. The manuscript management system is completely online and includes a very quick and fair peer-review system, which is all easy to use. Visit http://www.dovepress.com/ testimonials.php to read real quotes from published authors. 